\title{
Statistical Criteria for Modelling of Water Desorption Isotherms of Sugars. Estimation of Sucrose Hygroscopic Properties from Glucose and Fructose Data
}

\author{
Ramón Moreira*, Francisco Chenlo, María D. Torres, Diego M. Prieto \\ Department of Chemical Engineering, Universidade de Santiago de Compostela, Lope Gómez de Marzoa St, \\ Santiago de Compostela, E-15782, Spain. \\ E-mail: ramon.moreira@usc.es
}

\begin{abstract}
Experimental water desorption isotherms of glucose, fructose and sucrose were determined at different temperatures $\left(20,35,50\right.$, and $\left.65^{\circ} \mathrm{C}\right)$ using a static gravimetric method. Saturated salt solutions were selected to obtain different water activities from 0.09 to 0.91. All tested isotherms were type III following Brunauer's classification. The experimental data were satisfactory fitted by Henderson and Iglesias and Chirife models. A complete statistical analysis was performed, determining that Henderson model was more suitable to fit the desorption isotherms of tested sugars, since it satisfied all the rejection criteria and showed, in all studied cases, the highest values of lumped measure for the goodness of fit. Predicted water desorption isotherms of sucrose from the experimental sorption isotherms of its individual monomers (glucose and fructose), in moles of water per mol oxygen, nicely matched with those obtained experimentally.
\end{abstract}

Keywords: Equilibrium moisture content, henderson model, iglesias and chirife model, temperature, water activity.

\section{Nomenclature}

$\mathrm{A}$

A

$\mathrm{A}_{1}, \mathrm{~A}_{2}$

$\mathrm{a}_{\mathrm{w}}$

B

$\mathrm{B}_{1}, \mathrm{~B}_{2}$

$\mathrm{b}_{1}, \mathrm{~b}_{2}, \mathrm{~b}_{3}, \mathrm{~b}_{4}, \mathrm{~b}_{5}, \mathrm{~b}_{6}, \mathrm{~b}_{7}, \mathrm{~b}_{8}$

$\mathrm{C}_{1}, \mathrm{C}_{2}$

D

$\mathrm{D}_{2}$

E

$\overline{\mathrm{E}}$

$\mathrm{E}_{1}$

$\mathrm{F}_{1}, \mathrm{~F}_{2}$

J

$\mathrm{k}$

MRD

$\mathrm{m}_{3}$

$\mathrm{m}_{4}$

$\mathrm{n}_{1}$

$\mathrm{n}_{2}$

$\mathrm{pi}_{\mathrm{i}}$

$\mathrm{R}^{2}$

RMSE
Henderson (Eqs. 1 and 10) parameter, kg d.b. $\mathrm{kg}^{-1}$

variance-covariance matrix (Eqs. 4 and B1), -

auxiliar variables (Eqs. C5, C6, C14 and C16), -

water activity (Eqs. 1 and 2), -

Henderson (Eqs. 1 and 11) parameter, -

auxiliar variable (Eqs. C3, C4, C13 and C14), -

parameters (Eqs. 10-13), -

Iglesias and Chirife (Eqs. 2 and 12) parameter, -

auxiliar variable (Eqs. C2, C3, C5, C11 and C12), -

Iglesias and Chirife (Eqs. 2 and 13) parameter, -

auxiliar variable (Eqs. C10, C11 and C13), -

moisture residual (Eqs. 7, 8, 9, A1 and C8), kg (kg d.b.) $)^{-1}$

mean moisture residual (Eq. C8), kg (kg d.b.) $)^{-1}$

auxiliar variable (Eqs. C1 and C2), -

auxiliar variable (Eqs. C1, C5, C10 and C13), -

Jacobian matrix (Eqs. 4, B1 and B2), -

number of parameter estimates (Eq. 8), -

mean relative deviation (Eqs. 3 and 9), -

third moment about the mean for the residual population (skewness measure) (Eqs. C6 and C7), -

fourth moment about the mean for residual population (kurtosis measure) (Eqs. C14 and C15), -

number of experimental points (Eqs. 8, 9, C4, C6, C7, C9, C12 and C14- C16), -

number of positive residuals (Eqs. D1 and D2)

number of negative residuals (Eqs. D1 and D2)

parameters (Eq. B2), -

coefficient of determination (Eqs. 3 and 7), -

root mean squared error (Eqs. 3 and 8), - 
$\overline{\mathrm{r}}$

$\mathrm{SE}_{\mathrm{m}}$

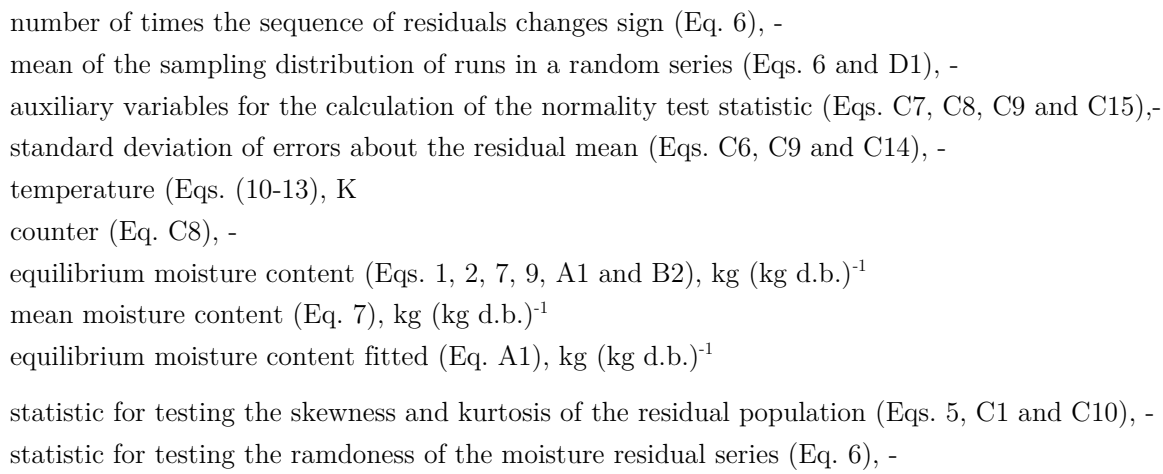

\section{Greek letters}

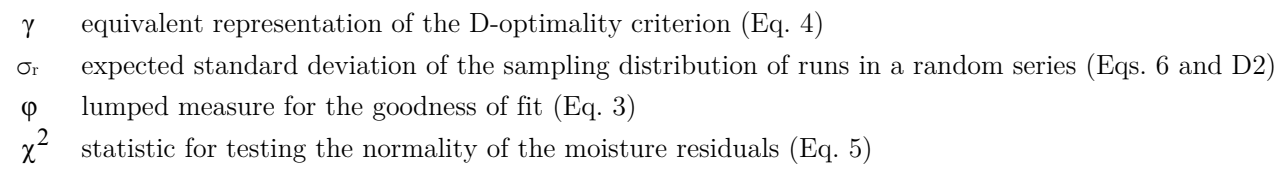

\section{Introduction}

Carbohydrates play a major role in biological and food systems. Sucrose is possibly the most important sugar for food manufacturing. It is a disaccharide that can be hydrolyzed to glucose (an aldehyde group, aldoses) and fructose (ketone group, ketoses) [1]. Both monosaccharides are also widely used as sweeteners in foodstuff. In general, sugars are hydrophilic to different degrees, depending on their structures which govern their plasticizing and moisturizing properties. The water sorption rate by sugars depends on their purity and homogeneity of crystal structure. The control of moisture content during processing of foodstuffs with high sugar content is basic in order to avoid the loss of sugars quality due to microbial and chemical spoilage [2]. Namely, the hygroscopic nature of sugars is an important factor on food moisture, texture, and quality [3].

The knowledge of the water sorption characteristics is essential in regard to stability and acceptability of food products, dehydration operation modelling, process equipment design, and evaluation of moisture changes during storage or selection of packaging materials $[4,5]$. Food systems typically exhibit Type II and III isotherms according to the BET classification [6]. Experimental water sorption isotherms are based on the determination of three properties: equilibrium moisture content, water activity and temperature (commonly at atmospheric pressure) [7]. In the literature, there are a large number of available empirical and semi-empirical equations to establish mathematical relationships among these three variables, which are usually evaluated by the experimental data fitting [8]. Another possibility is the prediction of water activity, at each moisture content and temperature, from fundamental laws and empirical expressions using prediction algorithms based on chemical composition of foodstuff $[9,10]$.

Estimating the hygroscopic properties of sugars at different temperatures could be valuable information in order to generate prediction models which will allow obtaining water desorption isotherms, in a wide temperature range of many food materials, taking into account their chemical composition [10]. This type of research is considered of great interest, since the existent literature shows an important discrepancy between different experimental water sorption isotherms for certain products. Also, the hygroscopic properties of many food products are not determined and the experiments to obtain the corresponding water sorption isotherms are time-consuming (usually several weeks). In these cases, the estimation of hygroscopic properties is interesting and the sorption characteristics of the main components (like sugars, starch, protein, fats, etc) should be well established. Information on sorption isotherm of sugars is scarce and limited to specific temperatures [11-13].

Therefore, the main objectives of this work are to determine the experimental equilibrium moisture content of glucose, fructose and sucrose over a wide range of water activities and temperatures of industrial interest as well as to select the appropriate mathematical model for predicting the water desorption isotherms at assayed temperatures. Another aim is to evaluate the possibility of predicting 
sucrose desorption isotherms from their monomers (i.e. glucose and fructose).

\section{Materials and Methods}

\subsection{Raw Materials}

Samples (about $0.2 \mathrm{~g}$ ) from two chemical reagents, D(+)-Glucose Anhydrous (Panreac Química S.A., Barcelona, Spain) and D-Fructose (Probus, S.A., Badalona, Spain), and sucrose PA-ACS (Panreac Química S.A., Barcelona, Spain), have been prepared to obtain the corresponding water desorption isotherms following the procedure previously reported [14]. Previously, the average particle size and particle size distributions of the crystalline sugars were determined using sieves of 500, 250, 125 and 80 $\mu \mathrm{m}$ (Table 1).

Table 1: Average particle size and particle size distributions of assayed sugars.

\begin{tabular}{|c|c|c|c|c|}
\hline Sugar fractions, $\mathrm{x}(\mathrm{m})$ & Average fraction size, $(\mathrm{m})$ & \multicolumn{3}{|c|}{ Mass fraction $(\%)$} \\
\hline & & Glucose $(\% \mathrm{w} / \mathrm{w})$ & Fructose $(\% \mathrm{w} / \mathrm{w})$ & Sucrose $(\% \mathrm{w} / \mathrm{w})$ \\
\hline$x>500$ & & $0.24 \pm 0.02^{\mathrm{c}}$ & $27.75 \pm 1.74^{\mathrm{b}}$ & $36.68 \pm 1.29^{\mathrm{a}}$ \\
\hline $250<\mathrm{x}<500$ & 375 & $2.11 \pm 0.09^{c}$ & $63.99 \pm 3.18^{\mathrm{a}}$ & $48.96 \pm 2.05^{\mathrm{b}}$ \\
\hline $125<\mathrm{x}<250$ & 187.5 & $31.06 \pm 1.14^{\mathrm{a}}$ & $5.81 \pm 0.49^{c}$ & $12.52 \pm 0.86^{\mathrm{b}}$ \\
\hline $80<\mathrm{x}<125$ & 102.5 & $14.61 \pm 0.63^{\mathrm{a}}$ & $2.45 \pm 0.22^{\mathrm{b}}$ & $1.84 \pm 0.11^{\mathrm{c}}$ \\
\hline$x<80$ & 40 & $51.98 \pm 2.71^{\mathrm{a}}$ & - & - \\
\hline Average particle size, $\mu \mathrm{m}$ & & $123.90^{\mathrm{b}}$ & $392.66^{\mathrm{a}}$ & $392.77^{\mathrm{a}}$ \\
\hline
\end{tabular}

Data are presented as mean \pm standard deviation. Data values in a row with different superscript letters are significantly different at the $p \leqslant 0.05$ level.

\subsection{Desorption Isotherms}

The equilibrium moisture content for desorption of sucrose, glucose and fructose were determined at 20 , 35,50 and $65^{\circ} \mathrm{C}$ using a static gravimetric technique. Firstly, samples were placed into an environment of $100 \%$ relative humidity for a couple of weeks in order to ensure the desorption process. Samples were placed into desiccators with different saturated salt solutions ( $\mathrm{KOH}, \mathrm{LiCl}, \mathrm{MgCl}_{2}, \mathrm{~K}_{2} \mathrm{CO}_{3}, \mathrm{Mg}\left(\mathrm{NO}_{3}\right)_{2}$, $\mathrm{NH}_{4} \mathrm{NO}_{3}, \mathrm{NaCl}, \mathrm{KCl}$ and $\mathrm{BaCl}_{2}$ ) at controlled temperature [15] in order to generate controlled humidity environment in a water activity range between 0.09 and 0.91 . The water activity values for the salt solutions at tested temperatures were estimated using the relationships previously reported [16]. The sugars samples (triplicate) were weighed and then placed into the desiccators with a little quantity of thymol to avoid the microbial degradation at water activities above 0.7. Samples were weighed in an analytical balance (Denver SI-234) (accuracy of $0.0001 \mathrm{~g}$ ) until they reach constant weight. Samples were equilibrated for approximately two months, as evidenced by constant values $( \pm 0.0003 \mathrm{~g})$ of three consecutive weight readings. After reaching equilibrium, the dry weight was determined after drying in a vacuum oven (Heraeus Vacutherm VT 6025) at $70^{\circ} \mathrm{C}$ and $15 \mathrm{kPa}$ [17] and the equilibrium moisture content was evaluated as an average of three measurements.

\subsection{Mathematical Modelling}

A large number of models have been previously proposed to describe the relationship between equilibrium moisture content and water activity [18]. Experimental data of this work were fitted by two simple models: Henderson [18] and Iglesias and Chirife [19]. Namely, Henderson developed an empirical model of two parameters with thermodynamic basis, which was proposed for the whole water activity range, and it is described by the following equation:

$$
X=\left[\frac{-\ln \left(1-a_{w}\right)}{A}\right]^{\frac{1}{B}}
$$


Iglesias and Chirife developed a model applied usually for high-sugar foodstuffs [20].

$$
\ln \left[\mathrm{X}+\left(\mathrm{X}^{2}+X_{0.5}\right)^{1 / 2}\right]=C a_{w}+D
$$

The parameters (A, B, C and D) of both models, Eqs. 1 and 2, were estimated by non-linear regression procedure employing Table Curve software (Jandel Scientific).

\subsection{Statistical Analysis}

Modelling data were analysed using one-factor analysis of variance (ANOVA). When the analysis of variance indicated differences among means, a Scheffé test was performed to differentiate means with $95 \%$ confidence $(\mathrm{p}<0.05)$. All statistical treatments were done using PASW Statistics (v.18, SPSS Statistics, USA).

In order to stablish the fittingness of tested models, a comprehensive statistical analysis was carried out taking into account several statistical indices proposed for the adequate selection of a food sorption isotherm model [21]. These indices are based on four rejection criteria, which may be summarised as follows: (1) if $\varphi$ shows low values, the model shows a poor adequacy to describe the experimental behaviour; (2) if $\gamma<1$ then a given model structure shouldn't be used to fit the experimental data; (3) if the value $x^{2} \geq 5.99$, the model should be rejected with $\mathrm{p}>0.95$ and (4) if the computed value $\mathrm{z}_{\mathrm{r}}$ $\geq 1.96$ the model should be rejected with $\mathrm{p}>0.95$. The corresponding equations are listed below, jointly with other commonly used statistics ( $\mathrm{R}^{2}$, RMSE and MRD).

$$
\begin{gathered}
\varphi=\frac{\mathrm{R}^{2}}{(\operatorname{RMSE})(\mathrm{MRD})} \\
\mathrm{Y}=\operatorname{det}\left(A^{-1}\right)=\operatorname{det}\left(\mathrm{J}^{\mathrm{T}} \mathrm{J}\right)>1 \\
\mathrm{X}^{2}=\mathrm{z}_{1}^{2}+\mathrm{z}_{2}^{2} \\
\mathrm{z}_{\mathrm{r}}=\frac{|\mathrm{r}-\mathrm{r}|-0.5}{\sigma_{\mathrm{r}}} \\
\mathrm{R}^{2}=\frac{\sum_{\mathrm{i}=1}^{\mathrm{n}}\left(\mathrm{X}_{\mathrm{i}}-\overline{\mathrm{X}}^{2}-\sum_{\mathrm{i}=1}^{\mathrm{n}} \mathrm{E}_{\mathrm{i}}^{2}\right.}{\sum_{\mathrm{i}=1}^{\mathrm{n}}\left(\mathrm{X}_{\mathrm{i}}-\overline{\mathrm{X}}^{2}\right.} \\
\mathrm{RMSE}=\sqrt{\frac{\sum_{\mathrm{i}=1}^{\mathrm{n}} \mathrm{E}_{\mathrm{i}}^{2}}{\mathrm{n}-\mathrm{k}}} \\
M R D=\frac{1}{\mathrm{n}} \sum_{\mathrm{i}=1}^{\mathrm{n}}\left|\frac{\mathrm{E}_{\mathrm{i}} \mid}{\mathrm{X}_{\mathrm{i}}}\right|
\end{gathered}
$$

Further detail can be found in above paper and the equations to calculate these statistical parameters are listed in the appendix.

In order to perform this comprehensive statistical analysis, parameters from Henderson and Iglesias and Chirife models were linearly correlated in function of the temperature for each sugar. Consequently, they were transformed into four-parameter models and the corresponding parameters (A, B, C and D) described as follows,

$$
\begin{aligned}
& A=b_{1}+b_{2} T \\
& B=b_{3}+b_{4} T \\
& C=b_{5}+b_{6} T \\
& D=b_{7}+b_{8} T
\end{aligned}
$$




\section{$3 \quad$ Results and Discussion}

\subsection{Experimental Desorption Isotherms}

The experimental water desorption data obtained in the range of studied temperatures (from 20 up to $65^{\circ} \mathrm{C}$ ) for glucose, fructose and sucrose are shown in Figures 1, 2 and 3, respectively. The desorption isotherms showed an increase of moisture content with the water activity following the shape of those isotherms belonging to the type III of Brunauer's classification [6]. Water desorption isotherms were significantly influenced by the temperature. At constant water activity, the equilibrium moisture content of tested sugars decreased with increasing temperature. Experimental data values are in the range and present the same form as the values reported in earlier works $[11,12]$ for water adsorption isotherms of sucrose, fructose and glucose at $25^{\circ} \mathrm{C}$, respectively. These results were also in well harmony with those previously reported for syrup powders [22] and with those found for food materials rich in sugars as sweet potato [23], apricot [20] or gooseberries [24].

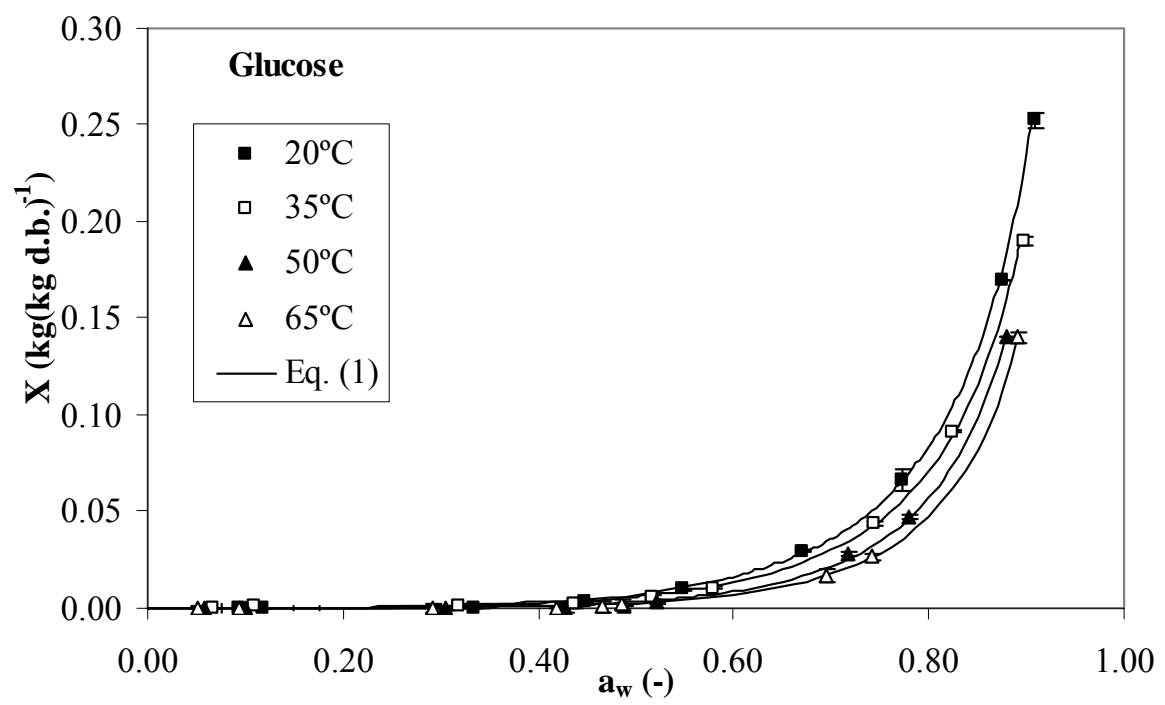

Figure 1: Experimental water desorption isotherms of glucose at different temperatures. Lines correspond to the Henderson model (Eq. 1).

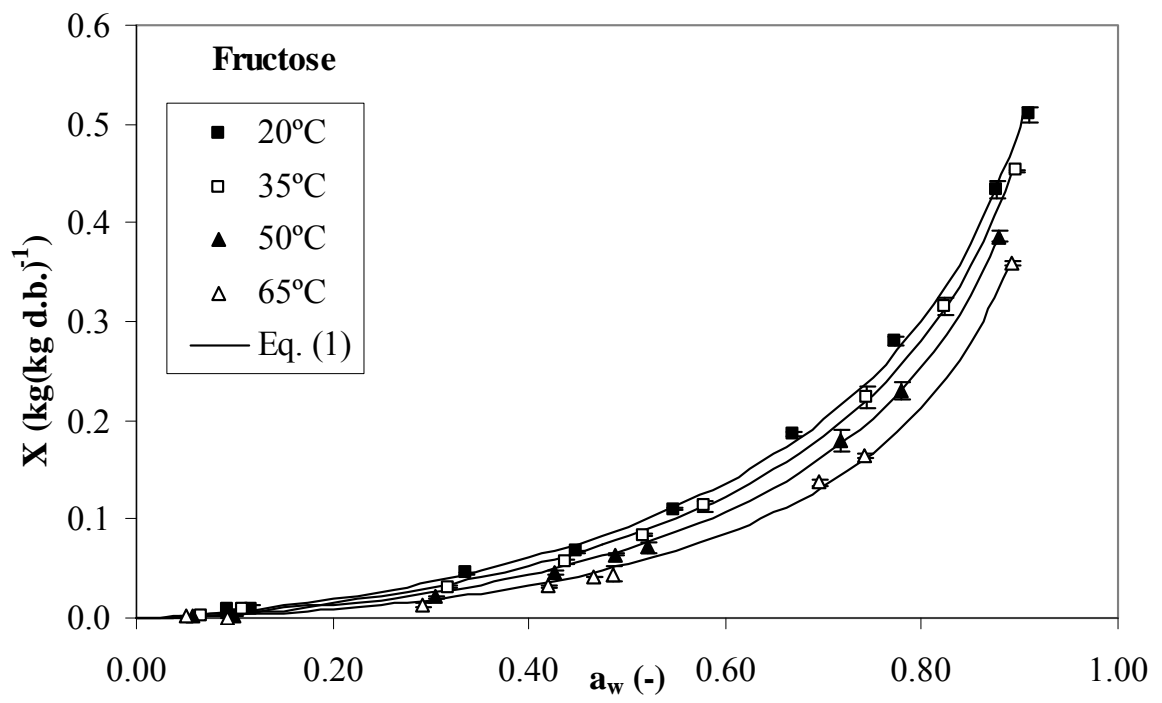

Figure 2: Experimental water desorption isotherms of fructose at different temperatures. Lines correspond to the Henderson model (Eq. 1). 


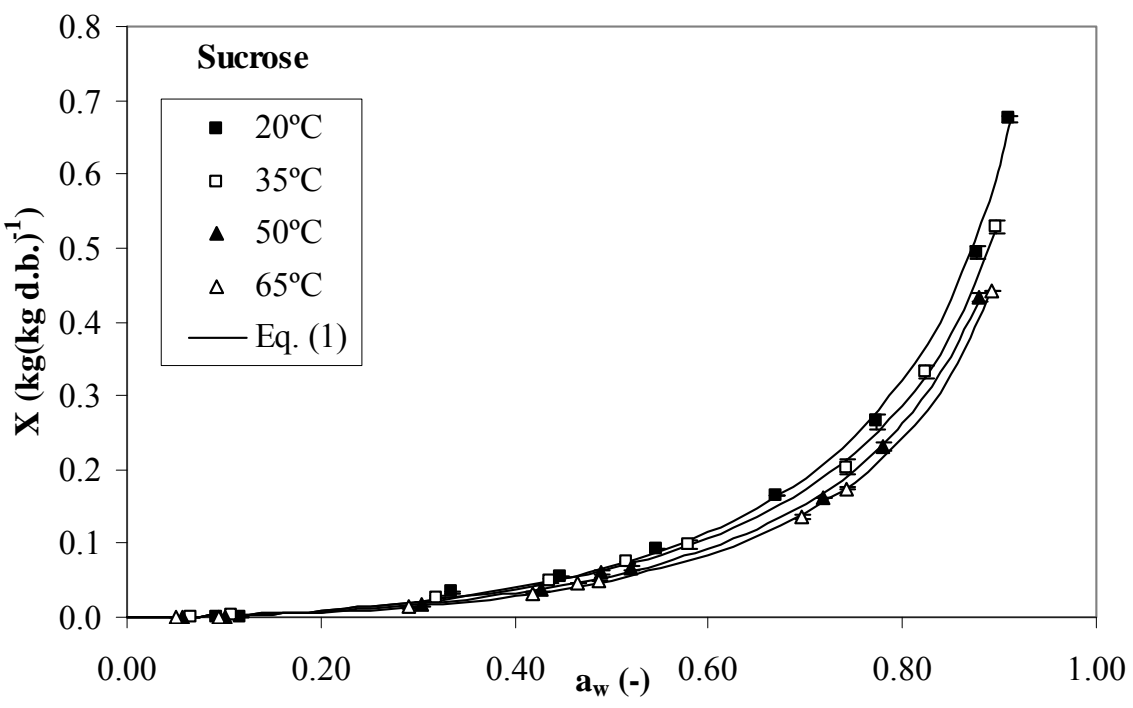

Figure 3: Experimental water desorption isotherms of sucrose at different temperatures. Lines correspond to the Henderson model (Eq. 1).

Comparing Figures 1,2 and 3, it can be observed, at constant temperature, that the equilibrium moisture content values for glucose were the lowest in the studied water activity range. At low and intermediate water activity values, fructose exhibited the largest equilibrium moisture contents, so that in this range fructose is the most hygroscopic sugar tested. It should be noted that, at water activity next to 0.8 (at $20^{\circ} \mathrm{C}$ ), a cross-point between desorption isotherms for fructose and sucrose has been found. Above this point, sucrose presented the largest equilibrium moisture contents. The water activity value, at which this cross-point was found, varied in a restricted range of (up to 0.77 at $65^{\circ} \mathrm{C}$ ) with increasing temperature. Considering the particle sizes presented in Table 1, it can be observed that fructose and sucrose with similar values of average particle size displayed a similar desorption behaviour, whereas glucose which exhibited the lowest particle size, clearly fetured the lowest values of moisture content. This agrees with previous results reported for chestnut flour and the corresponding starch with different average particle sizes [14].

\subsection{Prediction Sucrose Isotherms}

Figure 4 displays representative estimated desorption isotherm of sucrose at $65^{\circ} \mathrm{C}$ in comparison to experimental data. Note here that the ratio between moles of water per mole of each sugar was previously plotted against water activity for each temperature in order to obtain the corresponding empirical fittings $\left(\mathrm{R}^{2}>0.994\right)$ (data not shown). From these fittings, in terms of water activity, the moles of water per mol of oxygen were easily obtained for each individual sugar at each temperature. Adding these ratios for glucose and fructose and multiplying by a factor of 11/12 desorption isotherms of sucrose were got at different temperatures. This factor of 11/12 was used as sucrose presents 11 active centres whereas glucose and fructose present 6 each one [2]. In all cases, the experimental isotherms of the tested disaccharide (i.e. sucrose) were nicely predicted $\left(\mathrm{R}^{2}>0.990\right)$ from the corresponding sorption isotherms of their individual monomers (i.e. glucose and fructose). The authors are not aware that this prediction model had been previously reported elsewhere. 


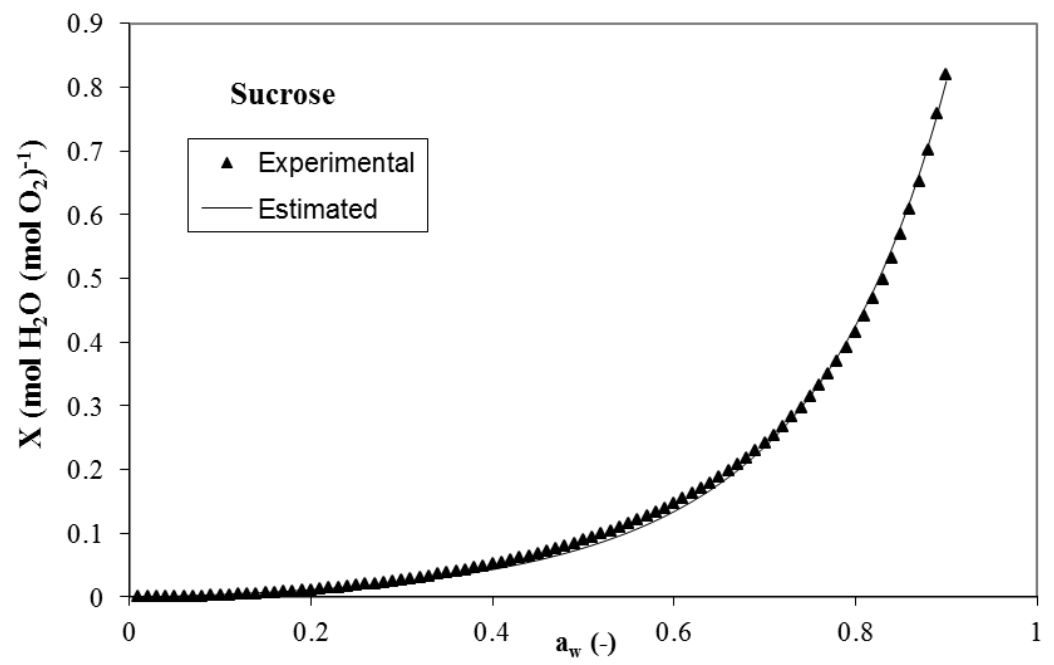

Figure 4: Comparison between experimental and estimated (from their individual monomers) of water desorption isotherms of sucrose at representative temperature, $65^{\circ} \mathrm{C}$.

\subsection{Model Selection}

The experimental data of all studied systems were satisfactorily fitted by Henderson and Iglesias and Chirife models (Eqs. 1 and 2). The corresponding model parameters for tested sugars at studied temperatures are listed in Table 2. For both models, all parameters depended significantly on temperature, excepting A parameter for glucose and B parameter for sucrose. Linear relationships were found between model parameters and temperature (Table 3). These outcomes are consistent with those previously reported for different foodstuffs $[25,26,27]$.

The values of the different parameters obtained from the comprehensive statistical analysis for two water sorption models are shown in Table 4 . The both models parameters widely satisfied the criteria proposed by [21] for the selection of a food sorption isotherm model, except $\chi^{2}$ parameter for glucose fitted by means of Iglesias and Chirife model that is closed to the boundary. The authors explained that in the case that tested models satisfied all the rejection criteria, the selected model in order to fit the water isotherms would be the one that shows the highest value of $\varphi$. Following this consideration and paying attention in Table 4 it can be observed that Henderson model showed the highest values of $\varphi$ in all cases, because it presented the highest $\mathrm{R}^{2}$ values and the lowest values of MRD and RMSE. Consequently, the Henderson model was completely satisfactory and adequate to fit the desorption isotherms for glucose, sucrose and fructose.

Table 2: Values of Henderson and Iglesias and Chirife models parameters (Eqs. 1 and 2) for desorption isotherms from glucose, fructose and sucrose at several temperatures.

\begin{tabular}{llllllllllllll}
\hline Parameters & \multicolumn{1}{c}{ Glucose } & \multicolumn{1}{c}{ Fructose } \\
\hline $\begin{array}{l}\text { Temperature } \\
\text { (品C) }\end{array}$ & 20 & 35 & 50 & 65 & 20 & 35 & 50 & 65 & 20 & 35 & 50 & 65 \\
\hline $\mathrm{A}$ & $3.91 \pm$ & $3.91 \pm$ & $3.91 \pm$ & $3.91 \pm$ & $3.79 \pm$ & $3.86 \pm$ & $3.94 \pm$ & $4.04 \pm$ & $3.00 \pm$ & $3.13 \pm$ & $3.32 \pm$ & $3.47 \pm$ \\
& $0.01^{\mathrm{a}}$ & $0.02^{\mathrm{a}}$ & $0.01^{\mathrm{a}}$ & $0.02^{\mathrm{a}}$ & $0.02^{\mathrm{d}}$ & $0.01^{\mathrm{c}}$ & $0.01^{\mathrm{b}}$ & $0.03^{\mathrm{a}}$ & $0.01^{\mathrm{d}}$ & $0.03^{\mathrm{c}}$ & $0.02^{\mathrm{b}}$ & $0.01^{\mathrm{a}}$ \\
$\mathrm{B}$ & $0.36 \pm$ & $0.33 \pm$ & $0.31 \pm$ & $0.29 \pm$ & $0.72 \pm$ & $0.69 \pm$ & $0.65 \pm$ & $0.61 \pm$ & $0.54 \pm$ & $0.54 \pm$ & $0.54 \pm$ & $0.54 \pm$ \\
& $0.01^{\mathrm{a}}$ & $0.02^{\mathrm{b}}$ & $0.02^{\mathrm{c}}$ & $0.01^{\mathrm{d}}$ & $0.03^{\mathrm{a}}$ & $0.01^{\mathrm{b}}$ & $0.02^{\mathrm{c}}$ & $0.01^{\mathrm{d}}$ & $0.01^{\mathrm{a}}$ & $0.01^{\mathrm{a}}$ & $0.02^{\mathrm{a}}$ & $0.02^{\mathrm{a}}$ \\
$\mathrm{C}$ & $9.69 \pm$ & $9.71 \pm$ & $10.6 \pm$ & $11.1 \pm$ & $4.32 \pm$ & $4.53 \pm$ & $4.82 \pm$ & $5.12 \pm$ & $5.60 \pm$ & $5.73 \pm$ & $5.75 \pm$ & $5.89 \pm$ \\
& $0.02^{\mathrm{c}}$ & $0.01^{\mathrm{c}}$ & $0.03^{\mathrm{b}}$ & $0.02^{\mathrm{a}}$ & $0.02^{\mathrm{d}}$ & $0.03^{\mathrm{c}}$ & $0.03^{\mathrm{b}}$ & $0.04^{\mathrm{a}}$ & $0.05^{\mathrm{b}}$ & $0.04^{\mathrm{b}}$ & $0.03^{\mathrm{a}, \mathrm{b}}$ & $0.03^{\mathrm{a}}$ \\
$\mathrm{D}$ & -10.2 & -10.4 & -11.3 & -11.8 & -4.61 & -4.87 & -5.19 & -5.59 & -5.65 & -5.78 & -5.90 & -6.07 \\
& $\pm 0.1^{\mathrm{a}}$ & $\pm 0.1^{\mathrm{a}}$ & $\pm 0.1^{\mathrm{b}}$ & $\pm 0.1^{\mathrm{c}}$ & $\pm 0.03^{\mathrm{a}}$ & $\pm 0.02^{\mathrm{b}}$ & $\pm 0.04^{\mathrm{c}}$ & $\pm 0.03^{\mathrm{d}}$ & $\pm 0.03^{\mathrm{a}}$ & $\pm 0.02^{\mathrm{b}}$ & $\pm 0.04^{\mathrm{b}}$ & $\pm 0.03^{\mathrm{c}}$ \\
\hline
\end{tabular}


Data are presented as mean \pm standard deviation. Data values in a row with different superscript letters are significantly different at the $p \leqslant 0.05$ levelTable 3 : Linear relationships between Henderson and Iglesias and Chirife parameters and temperature, Eqs. 10-13.

\begin{tabular}{|c|c|c|c|}
\hline Parameters & Glucose & Fructose & Sucrose \\
\hline $\mathrm{A}$ & 3.91 & $5.3310^{-3} \mathrm{~T}+2.23$ & $1.0810^{-2} \mathrm{~T}-0.17$ \\
\hline B & $-1.4110^{-3} \mathrm{~T}+0.77$ & $-2.2710^{-3} \mathrm{~T}+1.38$ & 0.54 \\
\hline $\mathrm{C}$ & $3.3010^{-2} \mathrm{~T}-0.14$ & $1.7910^{-2} \mathrm{~T}-0.96$ & $3.6110^{-3} \mathrm{~T}+4.64$ \\
\hline $\mathrm{D}$ & $-3.7910^{-2} \mathrm{~T}+1.04$ & $-2.1710^{-2} \mathrm{~T}+1.80$ & $-9.3010^{3} \mathrm{~T}-2.91$ \\
\hline
\end{tabular}

Table 4: Values of parameters and indexes obtained from statistical analysis for desorption isotherms of glucose, fructose and sucrose fitted by Henderson (above, bold numbers) and Iglesias and Chirife (below) models.

\begin{tabular}{lccc}
\hline Parameters & Glucose & Fructose & Sucrose \\
\hline $\mathrm{R}^{2}$ (Eq. 7) & $\mathbf{0 . 9 9 9}$ & $\mathbf{0 . 9 9 8}$ & $\mathbf{0 . 9 9 8}$ \\
& 0.996 & 0.997 & 0.997 \\
\hline RMSE (Eq. 8) & $\mathbf{0 . 0 0 2}$ & $\mathbf{0 . 0 0 7}$ & $\mathbf{0 . 0 0 8}$ \\
& 0.005 & 0.008 & 0.009 \\
\hline MRD (Eq. 9) & $\mathbf{0 . 7 6 5}$ & $\mathbf{0 . 1 6 8}$ & $\mathbf{0 . 3 7 9}$ \\
& 0.789 & 0.172 & 0.385 \\
\hline$\varphi \quad$ (Eq. 3) & $\mathbf{7 2 6 . 1 1}$ & $\mathbf{9 1 0 . 2 8}$ & $\mathbf{3 2 4 . 8 6}$ \\
& 703.20 & 901.20 & 315.41 \\
\hline Y (Eq. 4) & $\mathbf{7 0 . 2 5}$ & $\mathbf{1 . 4 2 \times 1 0 ^ { 3 }}$ & $\mathbf{4 . 9 6 \times 1 0 ^ { 4 }}$ \\
& 16.10 & $1.28 \times 10^{3}$ & $1.02 \times 10^{3}$ \\
\hline$\chi^{2}$ (Eq. 5) & $\mathbf{5 . 4 0}$ & $\mathbf{2 . 1 7}$ & $\mathbf{4 . 9 0}$ \\
& 5.89 & 3.56 & 5.06 \\
\hline Zr (Eq. 6) & $\mathbf{1 . 1 8}$ & $\mathbf{1 . 8 5}$ & $\mathbf{1 . 1 8}$ \\
& 1.56 & 1.86 & 1.89 \\
\hline
\end{tabular}

\section{Conclusions}

Water desorption isotherms of glucose, fructose and sucrose are clearly influenced by the temperature. All water sorption isotherms can be classified as type III. Sorption isotherms of sucrose were satisfactorily estimated from isotherms of its individual monomers (glucose and fructose). From statistical analysis, the Henderson model nicely fitted the water desorption isotherms of crystalline tested sugars. Parameters of Henderson (A and B) and Iglesias and Chirife models varied linearly with temperature, except A and B parameter for glucose and sucrose, respectively. Further work should be made to extend the proposed selection statistical criteria to other foodstuffs sorption isotherms.

\section{Appendix}

A. Evaluation of and MRD,

$$
\begin{aligned}
& \varphi=\frac{\mathrm{R}^{2}}{(\mathrm{RMSE})(\mathrm{MRD})} \\
& \mathrm{MRD}=\frac{1}{\mathrm{n}} \sum_{\mathrm{i}=1}^{\mathrm{n}}\left|\frac{\mathrm{E}_{\mathrm{i}}}{\mathrm{X}_{\mathrm{i}}}\right|
\end{aligned}
$$

where, $\mathrm{E}_{\mathrm{i}}=\mathrm{X}_{\mathrm{i}}-\hat{\mathrm{X}}_{\mathrm{i}}$

B. Evaluation of 
where, $\quad A=\left(\mathrm{J}^{\mathrm{T}} \mathrm{J}\right)^{-1}(\mathrm{~B} 1), \mathrm{J}=\left[\begin{array}{ccc}\frac{\partial X_{1}}{\partial p_{1}} & \cdots & \frac{\partial X_{1}}{\partial p_{k}} \\ \vdots & \vdots \\ \frac{\partial X_{n}}{\partial p_{1}} & \cdots & \frac{\partial X_{n}}{\partial p_{k}}\end{array}\right]_{(\mathrm{B} 2)}^{\curlyvee=\operatorname{det}\left(A^{-1}\right)=\operatorname{det}\left(\mathrm{J}^{\mathrm{T}} \mathrm{J}\right)>1}$

C. Evaluation of,

$$
x^{2}=z_{1}^{2}+z_{2}^{2}
$$

where, $\mathrm{z}_{1}=\mathrm{E}_{1} \ln \left(\mathrm{F}_{1}+\sqrt{\mathrm{F}_{1}^{2}+1}\right)(\mathrm{C} 1), \mathrm{E}_{1}=\left(\frac{1}{\ln \sqrt{\mathrm{C}_{1}}}\right)^{0.5}(\mathrm{C} 2), \mathrm{C}_{1}=\sqrt{2\left(\mathrm{~B}_{1}-1\right)}-1(\mathrm{C} 3)$,

$\mathrm{B}_{1}=\frac{3\left(\mathrm{n}^{2}+27 \mathrm{n}-70\right)(\mathrm{n}+1)(\mathrm{n}+3)}{(\mathrm{n}-2)(\mathrm{n}+5)(\mathrm{n}+7)(\mathrm{n}+9)}(\mathrm{C} 4), \mathrm{F}_{1}=\frac{\mathrm{A}_{1} \sqrt{\mathrm{C}_{1}-1}}{\sqrt{2}}(\mathrm{C} 5), \mathrm{A}_{1}=\frac{\mathrm{m}_{3}(\mathrm{n}-2)}{\mathrm{s}^{3} \sqrt{\mathrm{n}(\mathrm{n}-1)}} \sqrt{\frac{(\mathrm{n}+1)(\mathrm{n}+3)}{6(\mathrm{n}-2)}}(\mathrm{C} 6)$,

$\mathrm{m}_{3}=\frac{\mathrm{n} \mathrm{SE}_{3}}{(\mathrm{n}-1)(\mathrm{n}-2)}(\mathrm{C} 7), \mathrm{SE}_{\mathrm{m}}=\sum_{\mathrm{i}=1}^{\mathrm{n}}\left(\mathrm{E}_{\mathrm{i}}-\overline{\mathrm{E}}\right)^{w}$ for $\mathrm{w}=2,3,4 \quad(\mathrm{C} 8), \mathrm{s}=\sqrt{\frac{\mathrm{SE}_{2}}{\mathrm{n}-1}}(\mathrm{C} 9)$ and,

$\mathrm{z}_{2}=\left[\frac{2}{9 D_{2}}\right]^{\frac{-1}{2}}\left[1-\frac{9}{D_{2}}-\sqrt[3]{F_{2}}\right](\mathrm{C} 10), \mathrm{D}_{2}=6+\frac{8}{C_{2}}\left(\frac{2}{C_{2}}+\sqrt{1+\frac{4}{C_{2}^{2}}}\right)$ (C11),

$\mathrm{C}_{2}=\frac{6\left(\mathrm{n}^{2}-5 \mathrm{n}+2\right)}{(\mathrm{n}+7)(\mathrm{n}+9)} \sqrt{\frac{6(\mathrm{n}+3)(\mathrm{n}+5)}{\mathrm{n}(\mathrm{n}-2)(\mathrm{n}-3)}}(\mathrm{C} 12), \mathrm{F}_{2}=\left[1+\mathrm{B}_{2} \sqrt{\frac{2}{\mathrm{D}_{2}-4}}\right]^{-1}\left[1-\frac{2}{\mathrm{D}_{2}}\right](\mathrm{C} 13)$,

$\mathrm{B}_{2}=\frac{\left|\mathrm{m}_{4}\right|(\mathrm{n}-2)(\mathrm{n}-3)}{\mathrm{s}^{4}(\mathrm{n}-1)(\mathrm{n}+1) \sqrt{\mathrm{A}_{2}}}(\mathrm{C} 14), \mathrm{m}_{4}=\frac{\mathrm{n}(\mathrm{n}+1) \mathrm{SE}_{4}}{(\mathrm{n}-1)(\mathrm{n}-2)(\mathrm{n}-3)}-\frac{3 \mathrm{SE}_{2}^{2}}{(\mathrm{n}-2)(\mathrm{n}-3)}(\mathrm{C} 15)$,

$\mathrm{A}_{2}=\frac{24 \mathrm{n}(\mathrm{n}-2)(\mathrm{n}-3)}{(\mathrm{n}+1)^{2}(\mathrm{n}+3)(\mathrm{n}+5)}(\mathrm{C} 16)$

D. Evaluation of $\mathrm{z}_{\mathrm{r}}$,

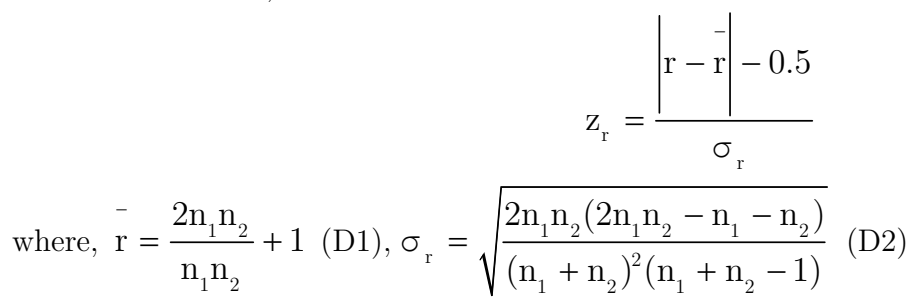

\section{References}

1. Levy DE, Fügedi P, The Organic Chemistry of Sugars. Boca Raton, USA: Taylor \& Francis Group, 2006.

2. Imeson A, Food stabilisers, thickeners and gelling agents. London, UK: Wiley-Blackwell, 2010.

3. Sivasankar B, Food Processing and Preservation. New Delhi, India, 2002.

4. Al-Muhtaseb A, McMinn W, Magee T., "Water sorption isotherms of starch powders. Part 2: thermodynamic characteristics," Journal of Food Engineering, vol. 62, pp. 135-142, 2004.

5. Koloor RT, Jayas DS, White NDG, "Adsorption and desorption characteristics of buckwheat," International Journal of Agricultural Biology, vol. 8, pp. 327-329, 2006. 
6. Brunauer S, Deming LS, Deming WE, Teller E, "On a theory of the Van der Waals adsorption of gases," Journal of Ameican Chemistry Society, vol. 62, pp. 1723-1732, 1940.

7. Bell LN, Labuza TP, Moisture Sorption: Practical Aspects of Isotherm Measurement and Use. St. Paul, USA: American Association of Cereal Chemists, 2000.

8. Moreira R, Chenlo F, Torres MD, Silva C, Prieto DM, Sousa AMM, Hillou L, Gonçalves MP, "Drying kinetics of biofilms obtained from chestnut starch and carrageenan with and without glycerol," Drying Technology, vol. 29, pp. 1058-1065, 2011.

9. Herman E, De la Cruz J, García MA, "Prediction of pineapple sorption isotherms using the Ross equation" Drying of Technology, vol. 17, pp. 915-923, 1999.

10. Moreira R, Chenlo F, Torres MD, "Simplified algorithm for the prediction of water sorption isotherms of fruits, vegetables and legumes based upon chemical composition," Journal of Food Engineering, vol. 94, pp. 334-343, 2009a.

11.Ditmar JH, "Hygroscopicity of sugars and sugar mixtures," Journal of Industrial Engineering Chemistry, vol. 27, pp. 333, 1935.

12. Makower B, Dye WB, "Sugar crystallization, equilibrium moisture content and crystallization of amorphous sucrose and glucose," Journal of Agriculture Food Chemistry, vol. 4, 72-77, 1956.

13.Penner EA, Schmidt SJ, "Comparison between moisture sorption isotherms obtained using the new vapor sorption analyser and those obtained using the standard saturated salt slurry method," Journal of Food Measurement Characteristics, vol. 7, pp. 185-193, 2013.

14.Moreira R, Chenlo F, Torres MD, Prieto DM, "Desorption isotherms and net isosteric heat of chestnut flour and starch," Food and Bioproducts Technology, vol. 4, pp. 1497-1504, 2009b.

15.Greenspan L, "Humidity fixed points of binary saturated aqueous solutions," Journal of Research Natural Bureau Standarda Section A. vol. 81, pp. 89-102, 1977.

16.Labuza TP, Knnane A, Chen JY, "Effect of temperature on the moisture sorption isotherm and water activity shift of two dehydrated foods," Journal of Food Science, vol. 50, pp. 385-392, 1985.

17.AOAC. Official methods of analysis. Washington, USA: Association of Official Analytical Chemistry, 2000.

18.Iglesias HA, Chirife J, "An empirical equation for fitting isotherms of fruits and related products," Journal of Institute Canada Science Technology, vol. 11, pp. 12-15, 1987.

19.Henderson SM, "A basic concept of equilibrium moisture," Agricultural Engineering, vol. 33, pp. 29-32, 1952.

20.Mrad ND, Bonazzi C, Boudhrioua N, Kechaou N, Courtois F, "Influence of sugar composition on water sorption isotherms and on glass transition in apricots" Journal of Food Engineering, vol. 111, pp. 403-411, 2012.

21.Ruiz-López II, Herman-Lara E, "Statistical indices for the selection of food sorption isotherm models," Drying Technology, vol. 27, pp. 726-738, 2009.

22.Farahnaky A, Mansoorib N, Majzoobia M, Badii F, "Physicochemical and sorption isotherm properties of date syrup powder: Antiplasticizing effect of maltodextrin," Food and Bioproducts Procesing, vol. 98, pp. 133-141, 2016.

23.Fasina OO, "Thermodynamic properties of sweet potato" Journal of Food Engineering, vol. 75, pp. 149-155, 2006.

24.Vega-Gálvez A, López J, Ah-Hen K, Torres MJ, Lemus-Mondaca R, "Thermodynamic properties, sorption isotherms and glass transition temperature of cape Gooseberry (Physalis peruviana L.)," Food Technology and Biotechnology, vol. 52, pp. 83-92, 2014.

25.Staudt PB, Tessaro IC, Marczak LDF, Soares RP, Cardozo NSM, "A new method for predicting sorption isotherms at different temperatures: Extension to the GAB model," Journal of Food Engineering, vol. 118, pp. 247-255, 2013.

26.Polachini TC, Betiol LFL, Lopes-Filho JF, Telis-Romero J, "Water adsorption isotherms and thermodynamic properties of cassava bagasse" Thermochimica Acta, vol. 632, pp. 79-85, 2016.

27.Brown A, Understanding Food. Principles \& Preparation. Merseyside, UK: Wadsworth Publishing Company, 2007. 